\title{
Beyond the Ivory Tower: Practice-led inquiry and post-disciplinary research
}

\author{
Keywords \\ Design, Hybrid artefacts, Postdisciplinarity, Practice-led research, Short film.
}

This address considers relationships between professional and postdisciplinary practices as they relate to practice-led design research. When viewed through territorial lenses, the artefacts and systems that many designers in universities develop can be argued as hybrids because they draw into their composition and contexts, diverse disciplinary fields. Procedurally, the address moves outwards from a discussion of the manner in which disciplinary designations, that originated in the secularisation of German universities during the beginning of the nineteenth century, became the template for how much knowledge is currently processed inside the academy. The paper then examines how these demarcations of thought, that included non-classical languages and literatures, social and natural sciences and technology, were disrupted in the 1970s and 1980s, by identity-based disciplines that grew inside universities. These included women's, lesbian and gay, and ethnic studies. However, of equal importance during this period was the arrival of professional disciplines like design, journalism, nursing, business management, and hospitality. Significantly, many of these professions brought with them values and processes associated with user-centered research. Shaped by the need to respond quickly and effectively to opportunity, practitioners were accustomed to drawing on and integrating knowledge unfettered by disciplinary or professional demarcation. For instance, if a design studio required the input of a government policy maker, a patent attorney and an engineer, it was accustomed to working flexibly with diverse realms of knowledge in the pursuit of an effective outcome. In addition, these professions also employed diverse forms of practice-led inquiry. Based on high levels of situated experimentation, active reflection, and applied professional knowing, these approaches challenged many research and disciplinary conventions within the academy. Although practice-led inquiry, argued as a form of postdisciplinarity practice, is a relatively new concept (Ings, 2019), it may be associated with Wright, Embrick and Henke's (2015, p. 271) observation that "post-disciplinary studies emerge when scholars forget about disciplines and whether ideas can be identified with any particular one: they identify with learning rather than with disciplines". Darbellay takes this further. He sees postdisciplinarity as an essential rethinking of the concept of a discipline. He suggests that when scholars position themselves outside of the idea of disciplines, they are able to "construct a new cognitive space, in which it is no longer merely a question of opening up disciplinary borders through degrees of interaction/integration, but of fundamentally challenging the obvious fact of disciplinarity" (2016, p. 367). These authors argue that, postdisciplinarity proposes a profound rethinking of not only knowledge, but also the structures that surround and support it in universities. In the field of design, such approaches are not unfamiliar. To illustrate how practice-led research in design may operate as a postdisciplinary inquiry, this paper employs a case study of the short film Sparrow (2017). In so doing, it unpacks the way in which knowledge from within and beyond conventionally demarcated disciplinary fields, was gathered, interpreted and creatively synthesied. Here, unconstrained by disciplinary demarcations, a designed artefact surfaced through a research fusion that integrated history, medicine, software development, public policy, poetry, typography, illustration, and film production. 